REVISTA DE LA CEPAL N 35

\section{Las regiones como espacios socialmente construidos}

\author{
Sergio Boisier*
}

El 2 de marzo de 1988 el Presidente del Perú promulgó la ley 24793 que créb la Región Grau, la primera región en América Latina configurada como una entidad territorial con personalidad juridica de derecho público dotada de autonomía. Puede preverse un fuerte efecto de demostración sobre otros paises en que la descentralización (territorial) ocupa un lugar importante en el discurso y el proyecto políticos.

Como en muchos otros casos, entre los cuales Francia puede considerarse a partir de 1982 como modelo, este acto fundacional del Perú genera una situación en que "la institucionalidad precede a la regionalidad" en el sentido de la creación - no exenta de justificado voluntarismo-- de una nueva estructura societal territorial. Esto plantea un formidable desafío profesional a la planificación regional puesto que muchas de estas nuevas regiones deben ser en verdad construidas tanto politica como socialmente. Para utilizar una feliz expresión de un politólogo, en no pocos casos tales regiones son verdaderas creaciones ex nihilo.

La constmucción politica dice relación con el establecimiento del aparato político y administrativo de las nuevas regiones, algo que puede hacerse incluso por decreto; la construcción social, por el contrario, debe hacerse desde y con la embrionaria sociedad regional. Construir socialmente una región significa potenciar su capacidad de autoorganización, transformando una comunidad inanimada, segmentada por intereses sectoriales, poco perceptiva de su identidad territorial y en definitiva, pasiva, en otra, organizada, cohesionada, consciente de la identidad sociedad-región, capaz de movilizarse tras proyectos políticos colectivos, es decir, capaz de transformarse en sujeto de su propio desarrollo. ¿Ingeniería social utópica? ¿Difícil pero insoslayable necesidad de una descentralizacion democrática? Ese es el dilema que se examina en el argumento del artículo.

-Experto en planificación regional del tlpes.
Not found as a finished product in natu$r e$, not solely the creation of human will and fantasy, the region, like its corresponding artifact, the city, is a collective work of art.

L. MUMrord

\section{Introducción}

Con mucha frecuencia y escasa originalidad se reitera que la planificación -en cualquiera de sus varias dimensiones- se encuentra en un estado de profunda crisis. Si bien esta afirmación es incuestionable, poco es lo que aporta al descubrimiento de la verdadera naturaleza de la crisis, algo que sin duda ayudaría a superarla.

Usando la forma metafórica, sería posible encontrar más de una similitud entre la planificación, latamente considerada, y la conquista ibérica del continente americano. Esta aventura de la humanidad fue una saga fundacional prácticamente sin parangón en la historia del hombre y se realizó con la ayuda tanto de la cruz como de la espada. La cruz, es decir, una doctrina, la fe católi$c a$, trató tal vez infructuosamente de dar un contenido moral, una ética, a la conquista, en particular en relación con el tratamiento de la población nativa; la espada, es decir, el poder politico, fue expresión indispensable de la voluntad de conquista y fundación y requisito básico para canalizar recursos y modelar la institucionalidad de los nuevos espacios incorporados al poder metropolitano.

La planificación debe ser entendida también como una saga fundacional. Según lo señaló en alguna oportunidad Michel Rocard, ex Ministro del Plan en Francia, la planificación global no es otra cosa que la organización de la sociedad en el tiempo, en tanto que la planificación regional (o el ordenamiento del territorio, en el lenguaje francés) no es sino la organización de la sociedad en el espacio. Tiempo y espacio son los ejes definitorios del cuadrante de la actividad humana. Planificar es, entonces, refundar la sociedad a lo largo de ambos ejes. Para esto, también la planificación requiere tanto una cruz, es decir, una doctrina, como una espada, esto es, poder politico.

Si se admite que el hombre es el único ser viviente capaz de pensar y de modelar su propio futuro y que este atributo deriva de su propio 
libre albedrío, de su impronta personal, habría que concluit que esa capacidad, que se confunde con la idea misma de la planificación, no puede jamás estar en crisis, en cuanto rasgo esencial del individuo. Puede sí entrar en crisis la doctrina $o$ la espada, o ambas al mismo tiempo. [Tal vez haya que entender de esta manera la manoseada crisis de la planificación!

En consecuencia, el desafío que enfrenta toda forma de planificación $-y$ en este caso la regional- es doble. Hay que construir o reconstruir la doctrina y es necesario ubicar o reubicar su práctica en la estructura de poder.

La reconstrucción doctrinaria debe comenzar desde los cimientos mismos del edificio teórico del desarrollo regional. Ello exige formularse algunos interrogantes básicos en todos los ámbitos de las ciencias sociales: ¿donde está el hombre?, ¿en qué momento de la especulación se borró la idea del hombre como objeto y sujeto del desarrollo?

Recuperada la noción fundamental del individuo en cuanto sujeto del desarrollo, será preciso convenir en que el desarrollo regional debe estar al servicio del hombre y no del territorio. De este punto debe partir todo esfuerzo de reconstrucción teórica.

El hombre aristotélico -animal politico- es también un ser apegado a un espacio vital, de cultivo o de caza -animal territorial-, que en función de su naturaleza gregaria se organiza en dos entornos: uno, el entorno social, que abarca desde la tribu a la compleja sociedad postindustrial; otro, el entomo territorial, que va desde la aldea tribal a la aldea global de McLuhan. El entorno, social o territorial, tiene que ser puesto al servicio de la persona humana, lo cual supone que el hombre es capaz de manejar su entorno o de intervenir en él.

El entorno territorial presenta varias escalas, que mantienen relaciones definidas con la posibilidad que el individuo tiene de intervenir en ellas. La primera, es la escala global, en la que la posibilidad de intervención para el individuo es nula, por lo que cabe considerarla una categoría puramente referencial. La segunda es la escala nacio$n a l$, entorno en el cual el individuo tiene capacidades indirectas de intervención a través de mecanismos político-electorales. La tercera es la escala regional, un entorno de dimensión media para el individuo, ni completamente "macro" ni completamente "micro", donde existen amplias posibilidades de intervención para alcanzar objetivos tanto individuales como colectivos. La cuarta escala es la local, escenario óptimo para la participación individual, pero de tamaño insuficiente para resolver cuestiones relativamente agregadas o de amplitud colectiva. En resumen, la base territorial se desarrolla como uno de los principales intereses sociales a cualquier nivel de agrupamiento. Por debajo del nivel nacional, tal interés se centra en la zona o región.

No obstante su ubicacion relativa en esta escala, el entorno regional aparece como un escenario extremadamente complejo. De hecho, a causa de su elevado grado de apertura e interconexión externas, es más complejo que escenarios territoriales superiores. Por tanto, debe ser pensado e intervenido mediante procesos estratégicos.

Comienza entonces a delinearse la idea de una estrategia - de intervención o de desarrollo regional-como pensamiento y como acción. Para entender claramente su sígnificado, tal vez sea útil recurrir a un simil con el ajedrez.

Quien tiene las piezas blancas inicia el juegoy en teoría dispone de $\mathbf{2 0}$ formas alternativas de apertura. Sin embargo, la experiencia socialmente acumulada sugiere que del abanico inicial de posibilidades, sólo tres o cuatro movimientos son recomendables. El jugador examina cada una de estas ya reducidas posibilidades y se pregunta acerca de la probable reacción del contrincante. Nótese que el adversario también dispone de 20 alternativas teóricas para partir, aun cuando la experiencia socializada las reduce de nuevo drásticamente en la práctica. Sin embargo, el segundo jugador cuenta con una información adicional: la movida previa de su oponente. Claro, por el momento todo esto sucede sólo en el cerebro del primer jugador, quien comienza de este modo a construir un verdadero árbol de probabilidades de acción/reacción. En otras palabras, diseña su estrategia, que es simultáneamente una forma selectiva de pensamiento - no evalúa todas las alternativas, sino sólo unas pocas-y una forma reactiva de acción, ya que para decidir cada movida toma en cuenta los movimientos anteriores y futuros de su oponente.

Para jugar ajedrez se requiere que los participantes conozcan las reglas del juego (por ejemplo, tipo de tablero que se usa, nombre y disposi- 
ción de las piezas, alternativas de movimiento de cada una de ellas y formas de término del juego). En otras palabras, para jugar (para intervenir) se requiere una teoria. Esta es inmutable vis a vis la realidad. Conocida la teoría, el ajedrez se juega de manera idéntica en cualquier parte.

En el campo ciertamente más complejo de la acción social, ia teoría necesaria para estructurar una estrategia de intervención no es inmutable ante la realidad; por el contrario, interactúa con ella. En consecuencia, el esfuerzo por refundar la doctrina del desarrollo regional, no debe descansar exclusivamente en la readecuación del cuerpo de teorías tradicionales o dominantes, puesto que ellas pueden mostrar una escasa vinculación con el medio societal de los páses no industrializados.

Esto significa que desde el punto de vista de la doctrina será necesario centrar el esfuerzo de reflexión en la inseparable trilogía realidaditeoríal estrategia ${ }^{1}$.

Para los efectos que acá interesan, la realidad está representada por: i) el sistema de relaciones sociales de producción, vale decir el sistema politico y económico; ii) la manifestación histórica, concreta y localizada del sistema, o sea, su estilo, "en esencia, políticas de desarrollo en acción más las contradicciones y conflictos que, deliberadamente o no, se están produciendo" (Graciarena, $1976)^{2}, y$ iii) el paradigma dominante de desarrollo regional, cuyas características esenciales son un marcado sesgo industrializante, el concomitante sesgo urbanizante y una notoria tendencia centralizadora en el plano de los sistemas decisorios y administrativos ${ }^{3}$.

Sobre esta última característica, conviene senalar que en tanto ella se refiere a las relaciones

\footnotetext{
${ }^{1}$ Una excelente discusión de las vinculaciones entre teo-
} ría, realidad y estrategias de desarrollo regional en América Latina, se encuentra en Helmsing y Uribe-Echeverrfa (1981) $y$, en una perspectiva más general, en Friedman y Weaver (1982) y Gore (1984), entre otros. territoriales de decisión, la centralización está estrechamente asociada a la nefasta separación entre sujeto y objeto de planificación. Esta podrá tener algún valor como dicotomía analítica en algunos campos de la planificación, pero introducida en el plano regional to ha hecho sino alimentar poderosamente las ya fuertes tendencias centralizadoras incorporadas en el paradigma. En esta dicotomía el sujeto fue y es el Estado central y, ciertamente, centralizado; y el objeto fue y es la región, precisamente considerada como artefacto a merced del sujeto y perfectamente incapaz en el sentido jurídico, social y político, porque, como es lógico, no se conceden ni se reconocen potestades ni capacidades a los objetos.

En consecuencia, es necesario disponer de una teoría del desarrollo regional que permita racionalizar la intervención en el entorno regional para ponerlo al servicio del hombre y que además: i) reconozca explícitamente la naturaleza del sistema sociopolitico en el cual se inscribe la región; por ejemplo, la existencia de una multiplicidad de actores sociales, llamados todos a desempeñar papeles legitimos, aunque quizá contradictorios; ii) admita la necesidad de coheren cia nacional/regional en función del estilo existente e identifique correctamente los límites de lo posible o los grados de libertad en materia de objetivos o políticas regionales; y iii) ofrezca posibilidades de modificar el paradigma dominante, sustituyendo la relación de subordinación sujetol objeto por una de interdependencia entre sujetos, 0 sea, transformando la región de objeto en sujeto, lo que significa reinsertar la planificacion regional en una nueva matriz de distribución del poder.

\footnotetext{
'Para un análisis sobre estilos de desarrollo y estrategias de desarrollo regional puede consultarse Hilhorst (1981).

'Una excelente sintesis del paradigma dominante se encuentra en Stohr y Taylor (1981).
} 


\section{La articulación entre el Estado y la región}

A medida que tiene lugar este proceso, aparecen dos sujetos o dos actores, el Estado y la región, ahora casi como un Estado. Por eso actualmente se tiende a definir la región como una organización política territorial dotada de personalidad jurídica de derecho público que goza de autonomia.

¿Qué repartición de funciones o qué división social del trabajo se produce entonces entre estos dos actores del desarrollo regional, uno antiguo y otro de aparición reciente? ${ }^{4}$.

Cuando se postula que el desarrollo regional es un proceso en el cual comparten responsabilidades tanto el Estado como la propia región, surge la necesidad de desentrañar las modalidades con que ambos actores se articulan, con el objeto de derivar recomendaciones sobre las políticas públicas más adecuadas para la promoción del desarrollo.

Dos son los tipos de procesos mediante los cuales el Estado condiciona el crecimiento económico de una región. Uno consiste en la asignación de los fondos públicos entre las regiones (gastos de capital y gastos corrientes). En tal sentido, a través del sector público de la economía el Estado cumple entonces una importante función de asignación interregional de recursos. Identificar y poner en práctica los procedimientos para guiar coherentemente este proceso han constituido, por lo demás, la función y modalidad tradicionales de la planificación regional.

Por otro lado, en cuanto único agente político con capacidad legítima de coacción, el Estado impone al resto de los actores económicos un determinado cuadro de política económica, de naturaleza tanto macro como sectorial, que produce impactos o efectos indirectos de variado signo y magnitud en cada región. En otras palabras, el cuadro general de la política económica no resulta neutral desde el puinio de vista regional.

Desde este ángulo, los efectos o impactos de un determinado conjunto de políticas económi-

\footnotetext{
"El "actor antiguo" es, al contrario de lo que podría pensarse, la region, cuya existencia como espacio social y politico es considerablemente anterior al Estado.
}

cas pueden resultar favorables a una región específica, en cuyo caso esta acción indirecta del Estado se suma al impacto directo provocado por la asignación de recursos a ella 0 , en otros casos, tales efectos pueden ser negativos, de manera tal que la acción indirecta anula e incluso sobrepasa lo que el mismo Estado hace directamente en la región. En ciertas circunstancias, las situaciones de este tipo darán origen, dentro de la planificación regional, a una función adicional, de carácter compensatorio, la que buscará anular, mediante procesos de negociación (política), tales efectos negativos, por ejemplo, vía un mayor gasto fiscal, cuando menos en algunas regiones.

En el mejor de los casos, entonces, la acción del Estado en una región determinada suscita condiciones favorables al crecimiento económico. Sin embargo, cuando se tienen en cuenta las diferencias que existen entre desarrollo y simple crecimiento económico, pronto se concluye que el paso de una situación a otra depende más de lo que la propia región pueda hacer-de su capacidad de organización social- que de las acciones del Estado.

En tal sentido, la articulación entre el Estado (como aparato público) y la región (en tanto actor social) resulta decisiva en los esfuerzos por promover un auténtico desarrollo regional. Sea cual fuere la cantidad de recursos que el Estado vuelque en una región, no conseguirá su desarrollo si ésta carece de una sociedad regional, compleja, con instituciones verdaderamente regionales, una clase política, una clase empresarial, organizaciones sociales de base, proyectos políticos propios, capaz de concertarse colectivamente. Es por ello que se produce una contradicción en los términos cuando se supone que el Estado puede por sí solo "desarrollar" una región.

Esta parece ser la cuestión crucial del desarrollo regional. Todo lo demás queda subordinado al logro de un arreglo activo entre el Estado y la región. Sus recursos naturales, posición geográfica, ventajas absolutas y comparativas son sin duda elementos importantes y factores positivos para estimular el crecimiento de las regiones, y un mejor equilibrio entre ellas, pero se trata de 
factores, en último análisis, supeditados a los asuntos políticos y sociales senalados.

Es por ello que en una concepción más actualizada e integral del desarrollo regional será preciso reconocer la existencia de tres funciones complementarias e interdependientes dentro de lo que habitualmente se ha denominado "planificación regional". Una primera función. de asignación de recursos, económica en su naturaleza, centralizada en su ejecución y exógena a la región; una segunda, de compensación, respecto de los impactos negativos de la política económica, de naturaleza política en lo esencial, desconcentrada en procedimientos y también exógena a la región; y una tercera función, de activación social, de naturaleza social y por cierto descentralizada y endógena a la región. Se trata, naturalmente, de una concepción más compleja y cuya puesta en práctica resulta más dificil. Al mismo tiempo, sin embargo, es potencialmente más eficaz y satisface el primer requisito de la reconstrucción teórica ${ }^{5}$.

\section{El itinerario de la construcción social regional}

¿Qué se requiere en este intento de propuesta teórica para transformar la región-objeto en una región-sujeto, cuestión central de este argumento?

Se requiere una distribución diferente del poder político en la sociedad, una suerte de nuevo "contrato social" entre el Estado y la sociedad civil, parcialmente expresada y organizada en regiones. A este nuevo "contrato social" se llega por medio de la descentralización políticoterritorial.

De aquí que desarrollo regional y descentralización territorial sean dos procesos que en la práctica definen un solo proceso autocontenido, de evidente naturaleza y dimensión tanto política como social $^{6}$.

La descentralización regional implica en casi todos los casos la necesidad de construir poltiticamente las regiones. Como se ha señalado en alguna oportunidad, hay que "politificar" las regiones. Es decir, hay que dotarlas de órganos que configuren una estructura política y administrativa autónoma de manera tal que las regiones pasen a tener categoría de entes politicos territoriales, que cuenten con personalidad jurídica de derecho público y gocen de autonomía. Estos organos propios son, con variadas denominacio-

\footnotetext{
${ }^{5}$ Este argumento es una apretada sintesis de las hipótesis sobre desarrollo regional expuestas in extenso en: Boisier (1982).

${ }^{6}$ Esta propuesta es desarrollada en Boisier (1987).
}

nes: una Autoridad Regional electa o semielecta, una Asamblea Legislativa Regional, un Consejo Económico y Social Regional, y los organismos de Administración Regional.

Para que este proceso adquiera, además, un carácter verdaderamente democrático es necesario que el receptor de la cuota de poder político entregada a la región, no sea sólo una estructura formal de organización o un grupo social hegemónico. Se requiere un depositario "socialmente adecuado", que no puede ser otro que la sociedad o comunidad regional organizada ${ }^{7}$. A su turno, ello implica en la práctica la necesidad de construir socialmente la región. Su desarrollo, entonces, reviste también una importante dimensión social. Construir socialmente una región significa potenciar su capacidad de autoorganización, transformando una comunidad inanimada, segmentada por intereses sectoriales, poco perceptiva de su identificación territorial y en definitiva pasiva, en otra que sea organizada, cohesionada, consciente de la identidad sociedadregión, capaz de movilizarse en pos de proyectos políticos colectivos, es decir, capaz de convertirse en sujeto de su propio desarrollo. Esta construcción es evidentemente una tarea de naturaleza social y de características particulares, porque no

\footnotetext{
${ }^{7}$ Como muchas de las regiones usadas en planificación son creaciones ex nihilo (Palına, 1983) o están cerca de serlo, dar por existente una sociedad o comunidad regional organizada puede ser casi una ficción.
} 
toda forma de organización social regional es funcional a un desarrollo regional equitativo y democrático. Acá se postula un desarrollo que presupone una sociedad regional organizada bajo el signo de la concertación y la participación social.

En un libro publicado recientemente en Chile, Jordi Borja, Teniente-Alcalde de Barcelona y especialista en Geografía Urbana, plantea un concepto muy semejante:

"La descentralización es un proceso de carácter global que supone por una parte el reconocimiento de la existencia de un sujeto [subrayado en el original] - una sociedad o colectividad de base territorial-capaz de asumir la gestión de intereses colectivos y dotado a la vez de personalidad sociocultural y político-administrativa y, por otra parte, la transferencia a este sujeto de un conjunto de competencias y recursos (financieros, humanos, materiales) que ahora no tiene y que podrá gestionar autónomamente en el marco de la legalidad vigente" (Borja, 1987) . $^{\mathrm{B}}$.

El desafio de "construcción social" regional estará siempre presente en situaciones en que la institucionalidad precede y pretende dar origen a la regionalidad. En ciertos casos (España puede ser un buen ejemplo cuando se piensa en Cataluña, Galicia y el País Vasco) la demanda regional es el gatillo de los proyectos descentralizadores y de desarrollo regional. En otros (Francia y en general Latinoamérica) la oferta gubernamental, que obedece a diferentes racionalidades, antecede a la demanda y sobreimpone al territorio una determinada regionalización ${ }^{9}$. De inmediato se

\footnotetext{
${ }^{8}$ En la misma obra, Borja sehala que... "Hay acuerdo general sobre que las divisiones territoriales deben basarse en unidades con personalidad (subrayado en el texto) social y/o cultural, con intereses comunes, que justifiquen la existencia de estructuras políticas representativas y que faciliten la participación cívica",

${ }^{9}$ En este contexto mantiene validez la siguiente afirmación hecha por J. Friedmann hace veinte afios: "A pesar de que cada una de las regiones de Chile tiene su propio perfil económico, las variaciones culturales entre ellas son pequenas. En têrminos generales los chilenos constituyen un pueblo bastante homogéneo y su apego al terruño natal es muy débil. Por esto las regiones del pais son más bien artefactos económicos que entidades orgánicas históricas y culturales, y carecen de toda expresión política. Las provincias, que son las unidades que las forman, no son sino subdivisiones administrativas conformadas siguiendo el modelo del sistema prefextorial francés" (Friedmann, 1969).
}

abre aquí un enorme e inconcluso campo de ensayo en relación con la forma en que se define una región y cómo ello se traduce en propuestas de regionalización. La historia de este asunto muestra la errónea primacía que adquirió la discusión sobre la naturaleza del contenedor (tamaño, limites, etc.), en circunstancias que debiera haberse privilegiado la estructura del contenido. En la práctica ello condujo al fracaso de la mayoría de los intentos de regionalización. Tal situación pone de inmediato de manifiesto la necesidad de "construcción social", según ha quedado en evidencia, por ejemplo, en Francia a partir de 1982.

"De forma general, ellas [las primeras experiencias de planificación descentralizada] han constituido un gran caldo de cultivo de la cultura de experimentación social... Han sido, al menos en algunos casos, una oportunidad para el reencuentro y para una discusión global entre grupos y entre intereses diversos, que a pesar de encontrarse en un mismo territorio se habían habituado a considerarse como extranjeros..."

"Las primeras experiencias de planificación descentralizada tal vez han tenido como interés inmediato principal el ser formas de autopedagogía colectiva, formas de aprendizaje de la responsabilidad colectiva de un territorio y de su porvenir. Aunque han estado lejos de generar un desarrollo autocentrado "en la base", han contribuido a reanimar las redes locales y regionales de contactos $y$ han hecho emerger o reemerger una conciencia territorial en una parte de la población y de sus líderes. Conciencia territorial que se forja tanto más nítidamente cuanto los agentes de un territorio tienen la oportunidad, por medio del trabajo en común, de constatar que ellos pueden tener intereses comunes" (Planque, 1985).

La tarea de construcción social comienza por la investigación sobre el número y tipo de agentes del desarrollo presentes en la región o, para ser más preciso, el número y tipo de agentes del desarrollo de la región y continúa con la identificación de los mecanismos de articulación que los aglutinan y que permiten hablar de un conjunto de agentes más que de una simple sumatoria de ellos. Estas son dos informaciones básicas para establecer mecanismos de activación social.

En un trabajo reciente, Wolfe hace una enumeración que en principio puede utilizarse directamente para identificar los agentes presentes 
en la region o de la región. Wolfe emplea las siguientes categorías: 1 , dirigentes políticos; 2. planificadores y demás tecnócratas; 3 . otros burócratas; 4 . capitalistas y empresarios; 5 . gerentes y otros tecnócratas; 6 . oficiales militares; 7 . jueces y abogados; 8 . dirigentes sindicales; 9 . dirigentes de asociaciones de profesionales; 10. propietarios de medios de comunicación; 11. académicos e intelectuales; 12 . dirigentes de organizaciones religiosas; 13 . dirigentes de organizaciones estudiantiles; 14 . dirigentes e ideólogos que rechazan la economía de mercado; 15 , dirigentes de movimientos de los pobres rurales y urbanos (Wolfe, 1987). Es importante tener en cuenta al observar esta lista de agentes que cada uno de ellos posee una racionalidad propia, no necesariamente coincidente. Es decir, cada uno de ellos interpreta de una cierta manera la cuestión regional y, en particular, su inserción en ella (los beneficios y los costos relativos a una posición dada), lo cual constituye una de las barreras principales a la concertación social al interior de la región.

A este conjunto de agentes se le aplica la primera regla corregida de la granja orwelliana, ya que si bien todos son "agentes", hay algunos "más agentes" que otros. En este sentido, debe recalcarse la importancia de aquellos que influyen de manera directa en el uso de recursos, ya sea movilizándolos desde otras regiones o bien incidiendo sobre la apropiación y reinversión $r e-$ gional del excedente.

Desde el punto de vista formal, estos agentes pueden actuar individual o colectivamente. En este último caso se agrupan en organismos públicos de naturaleza generalmente consultiva, tales como Consejos Regionales de Desarrollo u otros similares, en los que la legitimidad de la representación constituye un punto de crucial importancia $^{10}$.

Tanta trascendencia como el número de agentes presentes en una región tiene, por un lado, la distinción entre agentes de la región y agentes en la región y por otro, el estudio de las

\footnotetext{
${ }^{10}$ Este tema comienza a suscitar intenso debate en Chile, por ejemplo, donde en 1988 deben entrar en funcionamiento los Consejos Regionales de Desarrollo. Estos organismos de participación regional de carácter consultivo instalados por el Gobierno, obedecen a una buena idea, pero su representatividad y legitimidad son discutibles.
}

formas sustantivas de articulación entre ellos. La articulación o la adhesion de los agentes a un marco común (algo que dista todavía de la concertación) se expresa en un referente cultural compartido o en un proyecto político regional. El primero da cuenta de una identidad regional adscrita; el segundo, de una identidad regional adquirida. Cualquiera sea el caso, se trata del principio de identidad señalado por Touraine como el primero de los elementos definitorios de un "movimiento social" (regional en este caso). Como lo indica Laserna (1986), la identidad apela a ciertas condiciones de base compartidas colectivamente, que en el caso de la identidad cultural regional tienen que ver con el paisaje, las tradiciones, las formas de organización social, los mitos y las expresiones vinculadas al lenguaje, a la escritura, a la música y danza y a otras formas de expresión colectiva.

Desde el punto de vista de la aglutinación de los agentes, un proyecto político regional es un elemento alternativo y/o complementario de la cultura regional. En cada etapa de su historia, toda sociedad regional posee un proyecto político explícito o implícito, de objetivos múltiples o parciales, de naturaleza transformadora, conservadora o de compromiso, y que se refiere a la distribución más o menos coactiva del poder y de los recursos sociales. Hay que agregar que todo proyecto político se basa explícita o implícitamente en un conjunto de valores y creencias acerca de la estructura y modo de funcionamiento de la sociedad, del cual deriva una visión del tipo de sociedad futura deseada y del proceso de cambio social tendiente a materializarla. En este sentido, el proyecto político tiene una ideología predominante, la cual influye tanto en la identificacion de los fines sociales, como en la calificación de la legitimidad de los medios que han de utilizarse para alcanzarlos (Solari y otros, 1980). La existencia de un proyecto político regional presupone la de una "sociedad" regional que es, precisamente, la que debe ser construida para poder estructurar un proyecto regional. Hay que concluir, entonces, que la construcción social regional y la especificación del proyecto político son dos tareas simultáneas e interactuantes.

Sociedad regional, ideología y movimientos regionales parecen ser tres conceptos básicos dentro de la idea general de "construcción social regional". La noción de sociedad regional debe ser com- 
prendida como el espacio social, en un sentido amplio, donde se producen y reproducen un conjunto de prácticas y relaciones sociales particulares. Este conceptc alude a una unidad estructural y política en espacios sociales propios que interactúan permanentemente con otros y que se modifican de acuerdo con las fases del desarrollo nacional (F. Calderón, citado por Laserna, 1986). El espacio social y el espacio geográfico correspondiente están ligados por un mapeamiento recíproco o una relación biunivoca.

La ideología es el regionalismo. La expresión "regionalismo" representa estrictamente la idea de lo regional en acción, como una ideología, como un movimiento social o como el basamento teórico para la planificación regional (Schwartz, 1974) porque, aparte de ser un hecho físico, la región llega con el tiempo a ser una conciencia colectiva. En las ya temporalmente distantes palabras de H.W. Odum: "El regionalismo... representa la filosofía y la técnica de la autoayuda, del autodesarrollo, y la iniciativa mediante la cual cada unidad areal es no solamente ayudada, sino que también comprometida al pleno desarrollo de sus propios recursos y capacidades. Esto, por un lado, contrasta con la dependencia regional de la nación o con la submarginalidad de una región comparada con otras; por otro lado, contrasta también con la explotación hecha por fuentes externas. Presupone que la clave para la redistribución de la riqueza y para la igualdad de oportunidades, se encuentra en la capacidad de cada región para crear riqueza $y$, mediante nuevos alcances en el consumo de bienes, mantener esa capacidad y retener esa riqueza en programas bien equilibrados de producción y consumo" (citado por Friedmann y Weaver, 1982).

Los movimientcs sociales regionales -que expresan el regionalismo de una sociedad-son, en la definición de Laserna (1986), acciones colectivas que explicitan una identidad referida al espacio territorial, al que atribuyen o del que reivindican ciertas particularidades (económicas, culturales, étnicas, historicas, geográficas, políticas, etc.). Para conservar la amplia capacidad inclusiva de la base territorial de identidad, tales movimientos están enfrentados en forma incesante al imperativo de constituirse en ámbitos y mecanismos de concertación social, lo que los lleva a utilizar en su seno prácticas democráticas, a fin de que sus heterogéneos integrantes puedan expresarse.

Con los antecedentes expuestos es factible delinear una secuencia de acciones que conduzca al logro o al establecimiento de las regiones como cuasi-Estados, es decir, como sujetos resultantes de un proceso de construcción social regional, de elevado contenido descentralizador.

Este proceso se inicia con el análisis del tejido social, concepto que alude a la identificación de los agentes del desarrollo regional de la región (a la Wolfe) y de las formas de articulación que los entrelazan. Ya se señaló que la articulación sustantiva de estos agentes puede establecerse a través de la referencia a una cultura común o bien por intermedio de un proyecto político regional.

El tejido social define también el conjunto de organizaciones sociales de base (juntas vecinales, centros de madres, centros juveniles, clubes deportivos, etc. ...) mediante las cuales la población logra en forma asociativa ciertos objetivos que no tienen alcance político, en cuanto no afectan ni los recursos sociales ni la superestructura social. Son organizaciones a través de las cuales se expresa la "micro participación", algo similar al concepto de grass-root democracy. Hace ya bastante tiempo que Friedmann exploró una temática semejante, utilizando el concepto de "polo de desarrollo social" 1 .

La noción de proyecto político regional remite la construcción social al campo de las propuestas específicas que dan forma al proyecto. En general, éstas consisten en reivindicaciones de diversa naturaleza que apuntan a una diferente inserción de la región en el sistema político y económico nacional. Se trata de una cuestión permanente y no meramente coyuntural; por lo mismo, todo proyecto político es de largo plazo, en el entendido que éste, claro está, es algo que no comienza en un futuro distante, sino que aquí $y$ ahora. Del párrafo anterior, se sigue que todo proyecto político regional cuestiona explícita o implícitamente la dominación (cuantitativa y/o cualitativa) que se ejerce sobre la región.

\footnotetext{
${ }^{11}$ "Me referiré a las periferias activas como polos de desarrollo social... que poseen una alta capacidad potencial de organización propia para alcanzar un crecimiento económico sostenido. Propongo que denominemos esto, su capacidad de desarrollo social" (Friedmann, 1973). Obsérvese la similitud, pero sólo eso, con el concepto de capacidad de organización social regional.
} 
El regionalismo como ideologia del proyecto político regional debe ser asumido por una sociedad regional. La existencia de ésta, en cuanto manifestación concreta de un tejido social organico e ideologizado, da cuenta de una región socialmente construida, que expresa su propio proyecto político mediante movimientos regionales. La demanda principal, más permanente y generaliza$\mathrm{da}$, de estos movimientos es la demanda descentralizadora de una autonomía que desemboque en la figura de una región politicamente construida. Esta, a su turno, dará lugar jurídica y políticamente a la noción de región como cuasi-Estado, es decir, como una institución política dotada parcialmente de los atributos que se asignan al Estado en cuanto asociación de personas. Dicha noción reviste particular importancia para el reemplazo de la típica relación de subordinación entre el Estado y la región por una nueva relación concertada entre ambos sujetos, interdependiente y solidaria, que permita el surgimiento de nuevos instrumentos de planificación y gestión regionales, al estilo de los "contratos-plan" de la Francia descentralizada de Mitterrand ${ }^{12}$.

Una cuestion importante en este planteamiento tiene que ver con el estímulo a la concertación regional o con los impulsos para acometerla y la posterior conducción del movimiento regional. En un interesante aporte al estudio de los movimientos regionales, Abalos (1985) señala que el problema de la participación en ellos puede ser enfocado en dos niveles: uno se refiere a la capacidad de convocatoria para generar un respaldo masivo, mientras que el segundo considera el origen y la naturaleza de los líderes y activistas de estas causas. Según Abalos, los movimientos regionales tratan de movilizar verticalmente, esto es, sin hacer referencia a los problemas de status, de clases sociales y económicas, y de poder, que se dan intrar regionalmente. De esta manera sus proclamas son aglutinantes de los diversos sectores sociales y grupos ocupacionales.

Un segundo aspecto alude al origen de los activistas regionales. Abalos (1985) sostiene que, siendo imposible definirlo con exactitud, parece

\footnotetext{
${ }^{12}$ El contrato global es preparado por el Presidente del Consejo Reyional, en representación de la región, y el Administrador de la región por la República y en representación del Estado. Los contratos de planificarión tienen tres componentes principales: programas de acción especifica, identifi-
}

razonable suponer que aquellos que ejercen de líderes tienen, en lo tocante al problema político regional, habilidades, conocimientos y perspectivas superiores a los de la mayoría de la población local.

Probablemente esta capacidad de convocatoria y de concertación se halle potencialmente más desarrollada en instituciones (pertenecientes o establecidas en la región) que por su propia naturaleza y quehacer operan con enfoques multisectoriales y supraclasistas. Si a esto se agrega el prestigio social que confieren ya sea el saber científico o bien una postura moral, pareciera que instituciones como la Universidad o la Iglesia, entendida ésta en su sentido amplio, se encuentran en una posición privilegiada para oficiar de agentes "inductores" de la concertación social regional.

La concertación, sea entre la región y el Estado, sea entre los actores o agentes dentro de la propia region, puede ser considerada el resultado de verdaderos procesos de sinergia social, propios de un sistema abierto, como es toda regiớn. Por ello son aplicables acá las ideas de $\mathrm{Ha}$ ken, quien sostiene que en un sistema abierto, sus diversos componentes prueban constantemente nuevas posiciones mutuas, nuevos movimientos o procesos de reacción en los que siempre participan numerosos componentes individuales del sistema. Bajo la influencia de la energía constantemente aportada, uno o varios de estos movimientos o procesos se muestran superiores a los demás (Haken, 1984). En esta aventura refundacional de la planificación regional y de la descentralización, aquella energía no es sino la voluntad política colectiva de alcanzar una fase superior de desarrollo y de democracia (Boisier, 1987). A la implícita pregunta acerca de la "cantidad de energía política" que se requiere introducir al sistema para provocar tal proceso sinergético, debe responderse que se trata de una cantidad elevada, pero - según lo prueban los relativamente recientes casos de Francia y Españaalejados de toda utopia revolucionaria.

cados por objetivos y costos; determinacion concertada tanto. para modernizar la economia en las etapas de insumos y de productos del proceso productiva, como para promover una mayor justicia social; y estrategias para atender caracteristicas regionales específicas (Benko, 1987). 


\section{III}

\section{El Estado y la dominación regional}

Es imposible entender el subdesarrollo o el desarollo regionales sin acudir a la figura del Estado. Puesto que no todos los actores envueltos en una determinada situación regional son iguales, es indispensable tener en cuenta las formas de dominación y la distribución de los recursos de la sociedad (Solari y otros, 1980).

Pero ¿qué Estado o cuál concepción del Estado es la que interesa de manera principal? Desde luego, se alude a este agente más como figura política que como aparato institucional público. Por otra parte, se requiere utilizar la idea de Estado en sus múltiples facetas.

Si la tarea de construcción social regional desemboca, según se anotó, en el surgimiento de un cuasi-Estado regional, ello es precisamente para permitir a las regiones -por lo menos a algunas de ellas- articularse en forma adecuada con el Estado, lo cual supone a su vez sacar a luz las diversas racionalidades (politica, económica, jurídica, etc.) que explican y gufan la acción estatal.

O'Donell (1984) entiende por Estado "el componente específicamente político de la dominación en una sociedad territorialmente delimitada". Por su parte, Maranhao (I982) apunta: "El Estado es fundamentaimente una relación social de dominación y, en la medida en que fundamenta y organiza las relaciones de dominación a través de instituciones que habitualmente gozan del monopolio de los instrumentos de coerción dentro de un territorio definido, garantizando un sistema que articula de modo desigual los componentes de la sociedad civil, se revela en su faz de instrumento de clase" (Maranhao, 1982).

En cuanto a algunas de las funciones que el Estado desempeña gracias precisamente a su capacidad de dominación, es pertinente reproducir lo señalado por los autores recién citados. Así, por ejemplo, Maranhao apunta: "Sin embargo, en la medida en que esas instituciones del Estado son consideradas como poseyendo un derecho legíitimo [subrayado en el original] para garantizar el sistema de dominación social, el Estado aparece como mediador de los conflictos sociales". A su turno, O'Donell dice: "El Estado garantiza y organiza la reproducción de la sociedad qua capita- lista, porque se halla respecto de ella en una relación de 'complicidad estructural"'. Y Solari, Boeninger, Franco y Palma (1980) destacan tres funciones vinculadas al papel que le cabe en la planificación: el Estado aparece como el titular de la voluntad jurídica de la planificación; como actor frente a la sociedad civil; $y$, por último, como mecanismo de integración y sustento de orden político.

De estas citas fluye una cuestión importante: la dominación parece ser un atributo intrínseco al concepto mismo de Estado y ella es utilizada con el propósito, entre otros, de orientar el sistema económico hacia la consecución de determinados objetivos, expresados en una cierta función de preferencia social (en el lenguaje económico) o en un cierto proyecto político (en el lenguaje sociológico): por ejemplo, la maximización del ritmo de expansión o el logro de un determinado patrón de reparto de la riqueza.

Dada la importancia que se le atribuye, el concepto de dominación debe ser precisado. Es el propio O'Donell quien asume esta tarea al formular la siguiente definición:

"Por dominación (o poder) entiendo la capacidad, actual y potencial, de imponer regularmente la voluntad sobre otros, incluso, pero no necesariamente, contra su resistencia. La dominación es relacional: es una modalidad de vinculación entre sujetos sociales. Es por definición asimétrica, ya que es una relación de desigualdad. Esa asimetría surge del control diferencial de ciertos recursos, gracias a los cuales es habitualmente posible lograr el ajuste de los comportamientos y de las abstenciones del dominado a la voluntad -expresa, tácita o presunta- del dominante. No tiene sentido intentar un inventario exhaustivo de esos recursos, pero es útil distinguir algunos muy importantes como sustento de la dominación. El primero es el control de medios de coerción física, movilizables por sí o por intermedio de un tercero. Otro es el control de recursos económicos. Un tercero es el control de recursos de información en un sentido amplio, incluso conocimientos científico-tecnológicos. El último que interesa sefalar es el control ideológi- 
co, mediante el cual el dominado asume como justa y natural la relación asimétrica de la que es parte $y$, por tanto, no la entiende ni cuestiona como dominación" (O'Donell, 1984).

Para utilizar la idea de dominación en el contexto de las regiones, en otras palabras, para entender verdaderamente qué es lo que se quiere decir cuando se hace referencia a articulaciones del tipo dominación/dependencia en modelos "centro-periféricos" a la Friedmann, es necesario introducir un par de conceptos elementales de la teoria general de sistemas.

Un sistema es una colección de entidades u objetos, animados o inanimados, que reciben ciertas corrientes de entrada y se encuentran limitados a actuar en forma predeterminada sobre las entradas para producir cierta corriente de salida, con el objeto de maximizar alguna función de corrientes de entrada y salida ${ }^{93}$.

Ahora bien, hay que recordar que la esencia del análisis sistémico radica en el hecho, de que lo mejor para el todo no es necesariamente lo mejor para cada componente del sistema.

Expresado en otros términos, ello significa que para optimar la conducta del sistema se deben suboptimar los subsistemas.

Volviendo ahora al concepto de Estado, esta yez con una aproximación desde el campo del positivismo político más que desde la b́tica ideológica, el Estado aparece como una asociación de personas, o sea, como una sociedad creada por los hombres, con determinadas y conocidas características (membresía obligatoria, territorialidad, uso legitimo de la fuerza) que los individuos establecen para que esta sociedad o agrupación particular llamada Estado, ejecute ciertas tareas sociales que los propios individuos o sus asociaciones ahora intermedias, no pueden realizar (principio que dará origen al Estado subsidiario), o no quieren asumir (principio que dará origen al Estado suplementario y, por supuesto, centralizado). Una de las tareas encomendadas o delegadas en esta asociación de personas, será —en cualquiera de las dos situaciones indicadas - la de optimar la conducta del sistema social en términos de algunos resultados colectivamente aceptados, por ejemplo, maximizar el ritmo de incremento de la produc-

\footnotetext{
${ }^{13}$ Esta es la definición de sistema propuesta hace mucho iempo por R.B. Kresher. Ella aparece, por ejemplo, en Stanley (1966).
}

ción o alcanzar un determinado perfil de distribución del ingreso. El término sistema social denota en rigor una multiplicidad de sistemas, entre ellos el regional.

Se puede afirmar, entonces, que una de las tareas asignadas al Estado es, precisamente, al amparo de los estilos de desarrollo vigentes, maximizar el ritmo de aumento del producto social desde el punto de vista del conjunto de las regiones que definen un sistema regional, cuyo perimetro, por así decirlo, coincide con el todo. Para dar cumplimiento a un mandato de este tipo, el Estado deberá suboptimar uno o varios subsistemas (regiones). Es en este momento en que la dominación entra en juego, porque sólo haciendo uso de esa capacidad el Estado puede cumplix con su propia naturaleza y objetivo.

Este verdadero sentido y alcance de la articulación dominación/dependencia no ha escapado a la atención de algunos especialistas. Por ejemplo, Ch. Gore señala:

"Más aún, tan pronto como son establecidos mecanismos de coordinación para planificar las asignaciones de recursos al nivel regional, comienzan a ser evidentes los conflictos entre el logro de los objetivos nacionales y los objetivos regionales. El gobierno puede sostener que sus políticas se han diseñado para servir el 'bien común' de todos los habitantes del territorio nacional. Pero sin importar cómo se defina esta idea, el alcance del 'bien común a escala nacional será contradictorio con su logro a nivel regional y viceversa ${ }^{14}$. Una politica que hipotéticamente sirva el 'bien común' de los habitantes del territorio nacional no servirá el 'bien común' de la gente de algunas regiones de ese territorio..." (Gore, 1984).

Es así que el Estado limita las posibilidades de expansión material en algunas regiones, o sea, impone una dominación cuantitativa en ellas, impidiendo que maximicen su producción. En otros casos, algo más sutiles, hay dominación cualitativa, puesto que si bien se estimula al máximo la producción, se la orienta en una dirección o con un

\footnotetext{
${ }^{14}$ Esta es una cuestión claramente percibida en algunas experiencias nacionales. Por ejemplo, en Argentina se creó, en la década del 1950, el Consejo Federal de Inversiones (CrI), institución resultante de un acuerdo polftico entre las provincias, del cual no forma parte la Nación, y cuya finalidad es representar y defender los intereses del conjunto de ellas, distintos de los de la Nación (nota del autor).
} 
estilo que no corresponde a las necesidades regionales sino a necesidades nacionales y/o de otras regiones.

De hecho, la expansión territorial de un sistema capitalista expresado en un estilo "maximalista" de producción obedece a una lógica interna que orienta el sistema hacia la penetración de nuevos espacios, distintos de los lugares de acumulación tradicional. En ellos impone, a una escala reducida, un estilo en todo semejante al prevaleciente a escala nacional e introduce una relación de dominación indispensable para garantizar la reproducción del patrón de acumulación ${ }^{15}$.

La dominación que el Estado se ve obligado a imponer sobre ciertas regiones no le exige desplegar una acción directa en cuanto tal y ni siquiera a través de su estructura polícica transitoria, esto es el Gobierno. La dominación es mediatizada por las regiones más capitalizadas, cuyos intereses coinciden casi completamente con los "intereses generales" de la sociedad, representados por el Estado. ¿Qué diferencia significativa hay entre los "intereses" del país y los "intereses" de la región central (de acumulación tradicional) cuando ésta genera, por ejemplo, un 70 ó un $80 \%$ de la producción manufacturera, en un estilo en el cual la industria es el sector lider? ${ }^{\text {t6 }}$.

Este fenómeno de dominación que resulta de la naturaleza sistémica del conjunto regional se reproduce escalonadamente hacia abajo. Asi por ejemplo, la región Centro-Sur domina a la región Nordeste en el Brasil; y si se considerara a su vez a la región Nordeste como un sistema de varios Estados federados, se comprobaría probablemente que Bahía domina a Ceará y que en Ceará el municipio de Fortaleza domina a los otros municipios y asi sucesivamente.

Para toda región, es una cuestión fundamental "descubrir" quién la domina y el tipo de subordinación a que está sometida. Para algunas regiones, liquidar su articulación de dominación

\footnotetext{
${ }^{15}$ Numerosos autores -entre otros Harvey (1982), Boisier (1982), de Mattos (1989)- han discutido desde diversas perspectivas ideológicas la racionalidad de la expansión territorial del sistema capitalista.

${ }^{16}$ A título de ejemplo, el Estado de Sergipe, que forma parte del Nordeste del Brasil es "dependiente de y dominado por": a) el Estado brasileño; b) el Estado de São Paulo o; c) por cada uno y ambos o, puesto de otro modo, por Sāo Paulo en representación del Estado nacional.
}

significa abrir la puerta para transformar su propio crecimiento en desarrollo, en tanto que para otras, superar la dominación constituye un requisito para liberar su potencial de crecimiento. En ambos casos, aunque con caracteristicas diferentes, ésta es probablemente la función más importante de un esfuerzo planificado de desarrollo regional. Tarea que será también un componente básico del proyecto politico regional.

Pero ¿es posible romper una relación de dominación/dependencia entre, por ejemplo, la Región A (dominante) y la Región B (dependiente) si ello es el resultado de la doble lógica de la expansión territorial y de la optimación sistémica?

Consideremos inicialmente la dominación cuantitativa, vale decir aquella que se expresa en la imposición de un nivel y ritmo de producción inferiores a la capacidad potencial regional. Hay que convenir en que esa modalidad opera a través del proceso interregional de asignación de recursos ${ }^{17}$, que canaliza a estas regiones un flujo de recursos inferior al que la economía regional podría absorber sin generar presiones inflacionarias; $y$, también, mediante el posible impacto negativo del cuadro de la política económica global y sectorial. Es factible modificar el patrón interregional de asignación de recursos por vía de un mejoramiento significativo de la capacidad de negociación regional, fundada a su vez en la capacidad de organización social a ese nivel. Esta última se halla estrechamente asociada a las posibilidades de gestación de un proyecto político regional (Boisier, 1982).

La dominación cualitativa, esto es, la que se expresa en un condicionamiento de la expansión regional a las necesidades de la región dominante, se manifiesta en relación con las regiones de penetración inmediata del sistema, en las cuales se impone, según se señaló, un estilo similar al estilo global dominante ${ }^{18}$. En este contexto, producir una ruptura de la articulación dominación/ dependencia puede ser un desafío mucho más

\footnotetext{
${ }^{17}$ Suponiendo que no existan restricciones laterales de carácter estructural: por ejemplo, carencia de tecursos naturales o de población.

${ }^{18}$ Son en consecuencia, regiones de máxima prioridad real cuyo modo de producción se basa en la industrialización y en la urbanización. Corresponden a los casos de desarrollo regional usualmente considerados "exitosos". Son, en otras palabras, los nuevos centros de acumulación.
} 
complejo. En parte, porque existe el peligro de que la dominación adquiera además una dimensión ideológica, en el sentido que le atribuye $\mathrm{O}^{\prime} \mathrm{Do}$ nell, caso en el cual no hay fuerzas sociales con poder político que la cuestionen. $Y$ en parte, también, porque en el horizonte de estas regiones está su completa identificación (e incorporación) con las fuerzas dominantes de la dupla nacional/regional. El éxito de estas regiones es el éxito del sistema y de su particular estilo, y viceversa.
La concertación de la región con el Estado a fin de identificar y ejecutar proyectos en áreas (productivas o de investigación) que satisfagan necesidades compartidas puede ser en estos casos un buen camino para reducir la proporción de actividades locales al servicio de los intereses de la región dominante y aumentar en consecuencia la endogeneidad del crecimiento. Esta es condición y atributo del desarrollo de la región ${ }^{19}$. Ya se dijo que tal concertación sólo es posible con regiones política y socialmente construidas.

\section{La construcción social regional: ¿ingeniería social utópica?}

En el desafío de construir socialmente las regiones existe el peligro permanente de ceder a tentaciones centralizadoras, dominantes, autoritarias; en definitiva, exógenas a la región. Naturalmente que por esa vía la región nunca pasa de ser -ahora está claro-- objeto de manipulación social. El hombre, objeto, sujeto y beneficiario del desarrollo sigue convertido en una entelequia.

Cuando ello es así, se está frente a un proyecto de ingeniería social utópica, para usar la expresión de K. Popper. Ingeniería social utópica porque se agota en sí misma, sin conducir a parte alguna y sin conexión con las fuerzas sociales que podrían darle viabilidad. Según Popper, toda utopia social transformada en proyecto político -es decir, con control del poder-envuelve una fuerte tendencia al autoritarismo.

La construcción social regional sólo puede hacerse con y desde la comunidad regional, aunque ésta sea al comienzo incipiente y poco nitida. La ayuda exógena, normalmente imprescindible al comienzo como mecanismo inductor, debe cesar tan pronto sea posible.

Es necesario volver a una pregunta ya for" mulada: ¿quién puede o debe oficiar de inductor inicial en el proceso de poner en marcha a la comunidad regional? Dejando de lado el surgimiento de hechos, internos o externos, que pue- den en ocasiones desatar ese proceso ${ }^{20}$, la respuesta apunta al papel potencial de las organizaciones no gubernamentales.

Algunas de ellas operan preferentemente en planos muy básicos desde el punto de vista social $^{21}$, en tanto que otras se mueven en planos superestructurales y formales; por último, hay algunas que despliegan actividades en ambos planos (la Iglesia en particular). Dichas organizaciones cumplen al menos dos papeles significativos en el contexto de la "construcción social regional", al contribuir con su sola presencia a la densificación del tejido social, lo que tiene un valor intrínseco, y al funcionar en ciertos casos como "focos de inducción" de esta misma construcción. En este caso cuentan con la considerable ventaja de un alto grado de receptividad y

\footnotetext{
${ }^{18}$ Nuevamente los "contratos-plan" de Francia proveen un buen ejemplo de acuerdos para el desarrollo compartido de actividades y para el fomento compartido de la investigación cientsfica y tecnológica.

${ }^{20}$ Por ejemplo, catástrofes naturales que estimulan la solidaridad a acontecimientos pollticos o económicos que provocan una reacción colectiva defensiva.

${ }^{21}$ Las políticas económicas neoliberales ensayadas en América Latina a partír de los años setenta han hecho florecer una gran variedad de organizaciones no gubernamentales "básicas" que forman parte de las estrategias de sobrevivencia de los grupos más pobres y marginados de la población.
} 
aceptación por parte de la población, en particular en el segmento más marginal. Presentan en consecuencia una capacidad de articulación considerablemente mayor que las agencias del sector público, por lo general consideradas sospechosas de paternalismo y clientelismo, como mínimo. La universidad regional (cuando existe) y la Iglesia fueron indicadas más atrás como dos agentes inductores.

El tema del papel potencial de las organizaciones no gubernamentales en el desarrollo regional ha terminado por adquirir un perfil propio, por lo que su tratamiento excede los límites de este trabajo ${ }^{22}$. En cualquier caso, es necesario insistir en que la articulación y animación de la comunidad regional va de la mano con la especificación del proyecto político regional. Este suministra el telón de fondo contra el cual proyectar -es decir, conducir con objetivos establecidos previamente- la comunidad regional.

El proyecto político regional debe basarse en una ideología y en una estrategia de y para el desarrollo regional. En sus trazos gruesos, tal estrategia tiene en parte como objetivo final el cerramiento selectivo ${ }^{23}$ de la región y descansa en un procedimiento de planificación negociada ${ }^{24}$, que es, por pura definición, una modalidad participativa y concertada de planificación. En relación con los paradigmas conocidos de desarrollo regional, la estrategia $-y$ en consecuencia el proyecto político- - toma elementos de uno y de otro, en tanto se apoya en la articulación de los dos sujetos o actores ya mencionados: el Estado y la región.

La animación de la comunidad y la tarea paralela de especificar el contenido del proyecto político son dos asuntos con relación a los cuales tal vez sea útil conocer la respuesta a una pregunta clave: ¿qué pueden hacer los agentes del desarrollo por el desarrollo de su propia región? Esta pregunta obliga a estructurar una respuesta que saque a luz una explicación coherente del desarrollo regional en general (es decir, obliga a ex-

\footnotetext{
${ }^{22} \mathrm{El}$ número 29 (diciembre de 1983) de la Revisia latinoamericana de estudios turbano-regionales (EURE), que publica el Instituto de Estudios Urbanos de la Universidad Católica de Chile, está dedicado por entero al papel de las organizaciones no gubernamentales en el desarrolto regional.

${ }^{23}$ Esta es una conocida propuesta de Stöhr (1981).

${ }^{24}$ Esta propuesta fue planteada en Boisier ( 1979$)$.
}

plicitar una teoría). En la medida en que esa explicación no sea abstracta, y sí socialmente articulada, mostrará precisamente el papel de cada protagonista, desde los dirigentes políticos hasta los empresarios y los dirigentes sociales, cuyas actividades y responsabilidades deben ser enmarcadas en tareas institucionales y colectivas de la región.

Cabria ahora preguntar si todo el argumento desarrollado hasta el momento permite tener la certeza de haber completado el proceso de construcción social regional. La respuesta es inequívocamente negativa: nunca se puede tener la seguridad de que la puesta en práctica de una serie de acciones desembocará en la buscada "construcción social regional", De hecho, una respuesta taxativamente positiva volvería a $\mathrm{po}$ ner toda la cuestión en el campo de la "ingeniería social utópica" o en el del voluntarismo ingenuo. Aunque no existe receta alguna para alcanzar el objetivo de la construcción social regional en un plazo dado, es sin embargo fundamental contar por lo menos con un esbozo del objetivo. Ś́lo cuando se esté en posesión de una imagen aproximada de la sociedad y región que se desea, sólo entonces se puede empezar a considerar cuáles son los mejores caminos y medios para su realización y trazar un plan para la acción práctica. Como si las dificultades internas (a la región) con que tropieza el proceso de construcción social fuesen pocas, cabe senalar que otro escollo lo constituye el ambiguo marco externo a escala internacional aparte de, por qué no mencionarlas, las dificultades ideológicas, que naturalmente se transformarán en dificultades políticas prácticas.

La ambiguiedad del marco externo se refiere al doble signo que sobre los procesos regionales tienen las más importantes tendencias tecnológicas que se manifiestan en el ambito internacional, pero que repercuten claramente en el nivel local - por ejemplo las transformaciones en la tecnologia industrial y en la informática. El autor tuvo oportunidad de referirse marginalmente a estos temas en otro trabajo (Boisier, 1987). Las dificultades ideológicas se refieren a lo diffcil que les resulta a los marxistas en general aceptar la idea de los movimientos sociales (y en este caso, regionales) y la estrategia de concertación, en cuanto medios para promover el cambio social. Según señala Castells, "...por definición, el concepto de movimiento social como agente de transforma- 
ción social es estrictamente impensable en la teoría marxista. Existen luchas sociales y organizaciones de masas que se rebelan en defensa de sus intereses, mas no puede haber actores colectivos conscientes capaces de liberarse por sí mismos". (Castells, 1983, p. 400). El hecho es que, en muchas regiones, una parte de los agentes potenciales de desarrollo orientan su acción política en función de la teoría marxista y es de suponer entonces que al menos los más perspicaces de ellos no admitirán la consolidación de un proyecto político regional que por definición es antagónico a sus planteamientos.

Si se quiere colocar nuevamente al hombre en el centro de los procesos de desarrollo, debe aceptarse que la construcción social regional ha de ser un proceso oscilante entre tareas y objeti- vos a nivel tanto de microescalas (de acción, producción, movilización, etc.) como de macroescalas asociadas a la confrontación ideológica y a la internalización del cambio tecnológico. Para colocar el territorio regional al servicio del hombre será igualmente necesaria la construcción social y poltitica a ambas escalas.

Por ello es que este proceso se apoya tanto en la reflexión microcósmica del regionalismo de Gabriela Mistral: "En geografía comoen amor, el que no ama minuciosamente, virtud a virtud y facción a facción, el atolondrado que suele ser un vanidosillo, que mira conjuntos kilométricos y no conoce y saborea detalles, ni ve, ni entiende, ni ama tampoco", como en la macrocósmica invitación de Pablo Neruda a construir un mundo nuevo: "Sube a nacer conmigo, hermano"*.

\section{Bibliografia}

Abalos, J. (1985): Introducción à estudio de los movimientos sociales. El trimestre económico, $\mathrm{N}^{\circ}$ 206, vol, Ll1(2). México D.F.: Fondo de Cultura Económica, abril-junio.

Benko, G.B. (1987): French regional policy in the eariy $1980^{\prime}$ s. International Social Science Joumal, $N^{\circ} 112$ (Regional Science). Paris: Basil Blackwell/unesco.

Boisier, S. (1979): ¿Qué hacer con la planificación regional antes de medianoche? Revista de la CEPAL, $N^{\circ} 7$. Santiago de Chile, abril.

(1982): Política económica, organización social y desarollo regional. Cuadernos del ILPES $\mathbf{N}^{\circ} 29$. Santiago de Chile.

(1987): Los procesos de descentralización y desarrollo regional en el escenario actual de América Latina. Revista de la CEPAL, N*31. Santiago de Chile, abril.

Boisier, S. y otros (comps.) (1981): Experiencias de planificación regional en America Latina: una teoría en busca de una práctica. Santiago de Chile: ILPEs/stap.

Borja, J. (1987): Dimensiones teoricas, problemas y perspectivas de la descentralización del Estado, En Borja, Valdés, Pozo y Morales: Descentralización del Estado (rc]/FLACso/clacso). Santiago de Chile.

Castells, M. (1983): La ciudad y las masas. Madrid: Alianza Universidad Textos.

De Mattos, C. (1983): La dindmica concentredora y centralixadora en los procesos de formación de las estructuras territoriales latinoamericanas (CPRD-C/72). Santiago de Chile: ILPES.

Friedmann, J. (1969): Chile la déceda del 70. Santiago de Chile: Fundación Ford.

(1973): Urbanization, Planning and National Deselopment. Beverly Hills/Londres: Sage Publications.

Friedmann, J. y C. Weaver (1982): Territory and Function. Londres: Edward Arnold.

Gore, C. (1984): Regions in Question. Space, Development Theory and Regional Policy. Londres: Methuen.
Graciarena, J. (1976): Poder y estilos de desarrollo: una perspectiva heterodoxa. Revista de la CEPAL $\mathrm{N}^{\circ} 1$. Santiago de Chile, primer semestre.

Haken, H. (1984): Secreto de los éxitos de la naturaleza. Sinergébca: la doctrina de la acción de conjinto. Barcelona: Editotial Argos-Vergara.

Harvey, D. (1989): The Limits to Capital. Chicago: The University of Chicago Press.

Helmsing, B.H.J. y F. Uribe-Echeverría (1981): La planificación regional en América Latina: ¿̨teoria o práctica? En Boisier y otras (comps.) (1981): Experiencias de plarificación regional en America Latina: una teoria en busca de una práctica. Santiago de Chile: ILPES/SIAP.

Hilhorst, J. (1981): Estilos de desarrollo y estrategias nacionales de desarrollo regional. En Boisier y otros (comps.) (1981): Jbidem.

Laserna, R. (1986): Movimientos sociales regionales. Apuntes para la construcción de un campo empírico. Pensamiento iberoamericano, $\mathrm{N}^{\circ} 10$. Madrid: Instituto de Cooperación Iberoamericana, julio-diciembre.

Maranhao, 5. (1982): Estado e planejamento regional. Revista do Desenvolvimento Urbano e Regional. vol. $1, N^{\circ}$ l, Recife: Gentro de Estudos do Desenvolvimento Urbano e Regional.

* Las citas de Gabriela Mistral y de Pablo Neruda han sido extraídas respectivamente de "Regionalismo", fragmento de una conferencia dada en España con el título de "Breve descripción de Chile", incluida en Poesia y prosa de Gabriela Mistral (Selección y notas de Floridor Pétez), Santiago de Chile: Editorial Pehuen, 1984; y de "Alturas de Macchu Picchu", Canto General, Santiago de Chile, Aguilar, 1980. 
O'Donell, G. (1984): Apuntes para una teoría del Estado. En 0. Oszlak (comp.): Tromia de la burocracia estatal. Buenos Aires: Paidós.

Palma, E. (1983): La descentralización desde una perspectiva poltica (CPRD-D/90). Santiago de Chile: ILPES.

Planque, B. (1985): Decentralisation economique et decentralisation politique en France. The Canadian Journal of Regional Science, vol, vII, $\mathrm{N}^{\alpha}$ 9. Halifax.

Solati, A.E. y otros (1980): El praceso de planificación en América
Latina: escenarias, problemas y perspectivas. Cuadernos del «pss $\mathrm{N}^{\circ} 26$. Santiago de Chile.

Schwartz, M. (1974): Politics and Territory. The Sociology of Regional Persistence in Canada. Montreal y Londres: McGill-Queen's University Press.

Stanley, W. y D.R. Fraser Taylor (1981): Development from Above or Belowe? Londres: John Wiley and Sons.

Wolfe, M. (1987): Agentes del 'desarrollo'. Revista de la cEPAt $N^{\circ} 31$, Santiago de Chile, abril. 